\title{
MOTIVATION, SELF-IMAGE AND DEVELOPMENTAL TASKS INFLUENCE STUDENTS’ SCIENCE-RELATED CAREER CHOICE
}

\author{
Nina Bertels \\ Department of Chemistry Education, Freie Universität Berlin, Germany • nina.bertels@fu-berlin.de \\ Claus Bolte \\ Department of Chemistry Education, Freie Universität Berlin, Germany
}

\begin{abstract}
We examined in which way chemistry lessons influence students' intended career choice. Based on different theoretical approaches we are interested in answering the following question: Are the variables motivational learning environment, developmental tasks, self-to-prototype matching and selfconcept connected to the career choice? For this purpose we developed a questionnaire which includes the variables motivational learning environment, self-concept, self-image and prototypes and developmental tasks. The questionnaire was given to students of German schools (Hauptschule) and trainees of the chemical industry. A regression analysis showed that the variables partly influence the choice of career.
\end{abstract}

\section{Introduction}

\section{$1.1 \quad$ Problem}

It can be stated that many German students do not see opportunities for their futures, especially those without an academic background (Queisser, 2010, Seibel \& Kleinert, 2009). However, in Germany there are many job vacancies in the chemical industry. Students are not aware of these opportunities in the chemical industry, but even if they were they would not consider taking up a job in the scientific-technical field (Bertels \& Bolte, 2009; Elster, 2009).In our study we tried to find an answer to this problem.

According to Taskinen (2010) knowledge about jobs in the field of science is not related to students' career expectations. Thus the question arises how students are influenced by their chemistry lessons so that they tend to ignore the field of chemical industry and science. In our study we examined four different theoretical approaches which could probably help to explain students' ${ }^{\prime}$ science related career choice with regard to chemistry lessons.

These approaches are known as

- Motivational learning environment (Bolte, 2004),

- Developmental tasks (Schenk, 2005),

- Self-to-prototype matching (Kessels \& Hannover, 2002),

- Self-concept (Dickhäuser et al., 2002).

\subsection{Theoretical Framework}

We followed and combined the four theoretical approaches just mentioned. The first one addresses the experience and the assessment of chemistry teaching. Poor experiences in 
school science lessons mostly do not lead to science-related career aspirations (Aschbacher, Li \& Roth, 2010). Thus we want to investigate the impact of the motivational learning environment has on students' (intended) chemistry-related career choice. Bolte (2004) developed a questionnaire to investigate the motivational learning environment (MoLE) in different types of schools in Germany. He found seven different dimensions which can be used to analyse the motivational learning environment. These dimensions are

- Students' satisfaction,

- Subject orientation,

- Comprehension,

- Relevance of the topics,

- Possibility to participate,

- Class cooperation,

- Willingness to participate (Bolte, 2004).

A further approach which promises to yield insights into what is relevant for students is the aspect of educational experience and learner development. Within this pedagogical approach, the main emphasis is on the students' view of their own educational progress. One central theoretical basis of the learner development research is the concept of the developmental tasks formulated by Havighurst (1981). Havighurst states that people have to cope with different tasks in specific phases of their lives. The term "developmental task" was introduced by Havighurst as "a task which arises at or about a certain period in the life of the individual, successful achievement of which leads to his happiness and to success with later tasks, while failure leads to unhappiness in the individual, disapproval in the society, and difficulty with later tasks" (Havighurst, 1981, 2). Dreher and Dreher (1985) picked up on the work of Havighurst and conducted more specific research in this field focusing on the developmental tasks of adolescents. They found ten developmental tasks which young people have to work on, but not every developmental task can be addressed in chemistry lessons. Schenk (2005) defined six developmental tasks which should be dealt with in chemistry lessons. These tasks are:

- value (moral and ethic aspects),

- concepts (science related questions and beliefs),

- vocation (knowledge about different jobs and requirements to work in that jobs),

- self (knowledge about the own personality),

- gender (knowledge about gender specific roles),

- body (knowledge and acceptance of the own body).

Another factor which influences the career choice related to chemistry is self-toprototype matching. Studies (e.g. Chambers, 1983; Barman, 1999; Narayan, 2009) show that students have negative stereotypes of scientists. Hannover and Kessels (2002, 2004) investigated the field of prototypes in Germany. According to them, a prototype is the 
stereotypical image one has about typical representatives of specific groups. Whenever we choose a job, a university course or even a hobby, we compare our self-image with that of the prototype. If prototype and self-image match it is likely that we will choose that job, university course or hobby. Hence, if the students' prototype of people who work in chemical industry is rather negative (the picture of the 'mad scientist' comes to mind) then students are likely not to choose careers in science and technology.

The last approach, which should explain influencing factors in making important decisions such as the choice of future profession is the self-concept (eg. Eccles, 1983; Marsh \& Yeung, 1997; Köller et al., 2000).Within this framework we mainly focus on the study conducted by Taskinen (2010) which shows that self-concept correlates with the likeliness of taking up a scientific career. How our theoretically based assumptions fit to our hypothetical model is provided in Figure 1.

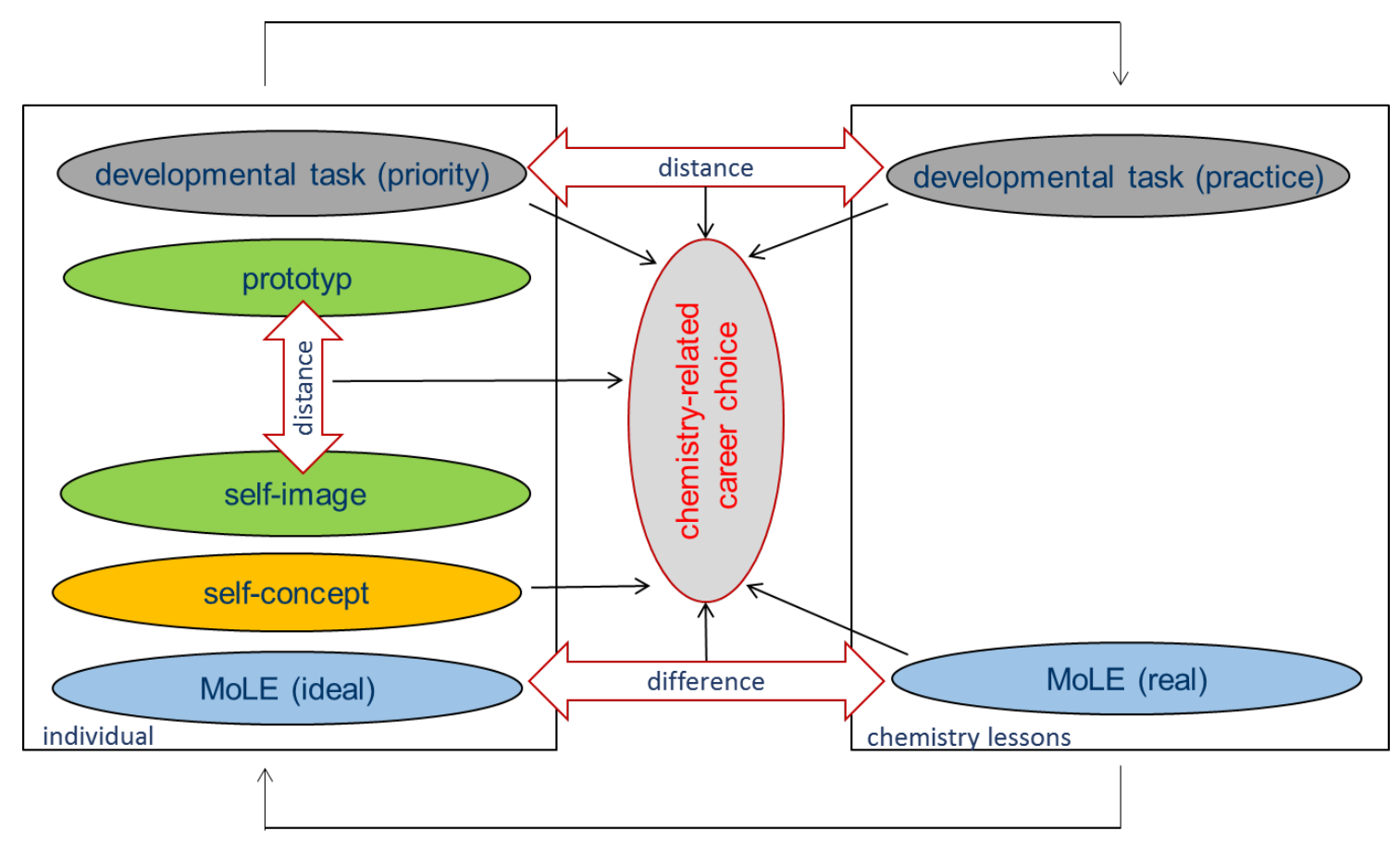

Figure 1 Hypothetical model

\subsection{Findings from our previous studies}

In previous studies (Bertels \& Bolte, 2009; Bertels \& Bolte, 2010) we examined students from 10 German schools ("Hauptschulen") (n=392) and trainees from a vocational school in the field of chemistry $(n=111)$. Regarding the four theoretical approaches we found the following results. 


\section{1) Motivational learning environment}

The motivational learning environment of chemistry lessons in Hauptschule was described mainly as unsatisfactory. On comparing Hauptschule-students and trainees we found that the assessment of the trainees from vocational schools was more positive (Bertels \& Bolte 2010).

\section{2) Developmental tasks}

We could also show that all developmental tasks mentioned by Schenk were considered as important by the students of both groups (Bertels \& Bolte, 2009).

Comparing the two groups of students, members of both groups complained about insufficient support when dealing with developmental tasks. Regarding the students' assessment of the developmental-task-scales we found that the assessments of students from vocational schools were even worse than those of the students from Hauptschule (Bertels \& Bolte 2010).

\section{3) Self-to-prototype matching}

Comparing the self-images and prototypes of the Hauptschule students and of the trainees we found differences as well. The Hauptschule students see themselves as more attractive, more socially competent, more creative but less selfish and less intelligent compared to the prototype they have of an employee in chemical industry. We can find the same tendencies in the results of the trainees but the difference between self-image and prototype is much smaller than in the group of Hauptschule students. All in all, the prototype students from Hauptschule have is rather negative and self-image and prototype do not match (Bertels \& Bolte 2010).

\section{4) Self concept}

Regarding the Hauptschule students their science related self-concept was lower than their school-related self-concept (Bertels \& Bolte, 2009). The science related self-concept of the trainees did not differ from their school related self-concept.

\section{5) chemistry-related career choice intention}

Most of the Hauptschule-students were also questioned regarding their aspiration to take up a career in the field of chemistry. Most of the Hauptschule-students did not express their intention to start a chemistry-related career. We were able to identify two groups (Bertels \& Bolte, 2015, in progress):

- Hauptschule-students with career choice intention $(n=47)$

- Hauptschule-students without career choice intention $(\mathrm{n}=\mathbf{2 7 7})$

\subsection{Research question}

The question in which we are interested now is: How are the variables of the four selected theoretical approaches (motivational learning environment, developmental tasks, self-toprototype matching and self-concept) connected to the career choice? 


\section{Method}

In order to answer our research question we developed an instrument containing questionnaires, some of which we adapted from other studies. One of the questionnaires was taken from Kessels and Hannover (2002). It includes a list of 35 adjectives which can be used to describe one's self-image and prototype. We also employed a questionnaire about the motivational learning environment (Bolte, 2004). The scale concerning the science-related career choice intention was adapted from Kessels and Hannover (2002). Using the results of this scale we separated the Hauptschule-students in two different groups. One group consists of students with a mean value of the scale "career choice intention" below the theoretical mean value (Hauptschule-students with career choice intention, $n=47$ ), another group with a higher mean value of the scale "career choice intention" (Hauptschule-students without career choice intention, $\mathrm{n}=277$ ).

In order to find out whether the six developmental tasks (value, concepts, vocation, self, gender, body) are important we formulated 52 items concerning the six tasks. We also developed a questionnaire (also 52 items) that examines in which areas chemistry lessons support the students in dealing with their developmental tasks (Bertels \& Bolte, 2009).

As we want to compare the results of students from Hauptschule who probably will not choose a career in the field of chemistry with trainees in chemical industry, we will give the questionnaire to Hauptschule-students (Grade 9) in Berlin and to trainees in the chemical industry.

After analyzing and comparing descriptive and variance-statistic results, two regression analyses will be conducted. In order to show how the (chosen) variables of the four theoretical approaches influence students' intended chemistry related career-choice we will take out a linear regression analysis. This analysis will contain the data of the Hauptschulestudents because the trainees have already chosen a career. The dependent variable of the linear regression analysis will be "career choice intention"scale (Kessels \& Hannover, 2002) The second analysis we want to carry out is a binary logistic regression analysis. Thus, we hope to find out which of the variables of the theoretical approaches may explain the membership to the group of Hauptschule-students (representing young adults without career aspirations in the field of chemistry) or to the group of trainees (who have already chosen a chemistry-related career). So the dependent variable is the membership to the group student or trainee.

\section{Results}

Our regression analyses include the data of different sample sizes. The linear regression analysis was carried out with the data of 324 Hauptschule-students. The binary logistic 
regression analysis is based on the data of 277 Hauptschule-students (Hauptschulestudents without career choice intention) and 111 trainees. ${ }^{1}$

Before we take a look at the descriptive statistic results we will focus on the quality of the questionnaires. The reliability of the scales we have formulated was acceptable (Cronbachs'a .619- . 946).

As a first step in our analyses we identified the variables of the four theoretical approaches which correlated with the dependent variables of the analysis in a statistically significant manner. After analyzing the correlations between the dependent variable and the other variables the following independent variables were assumed (see Table 1)

Table 1 Variables for the regression analyses

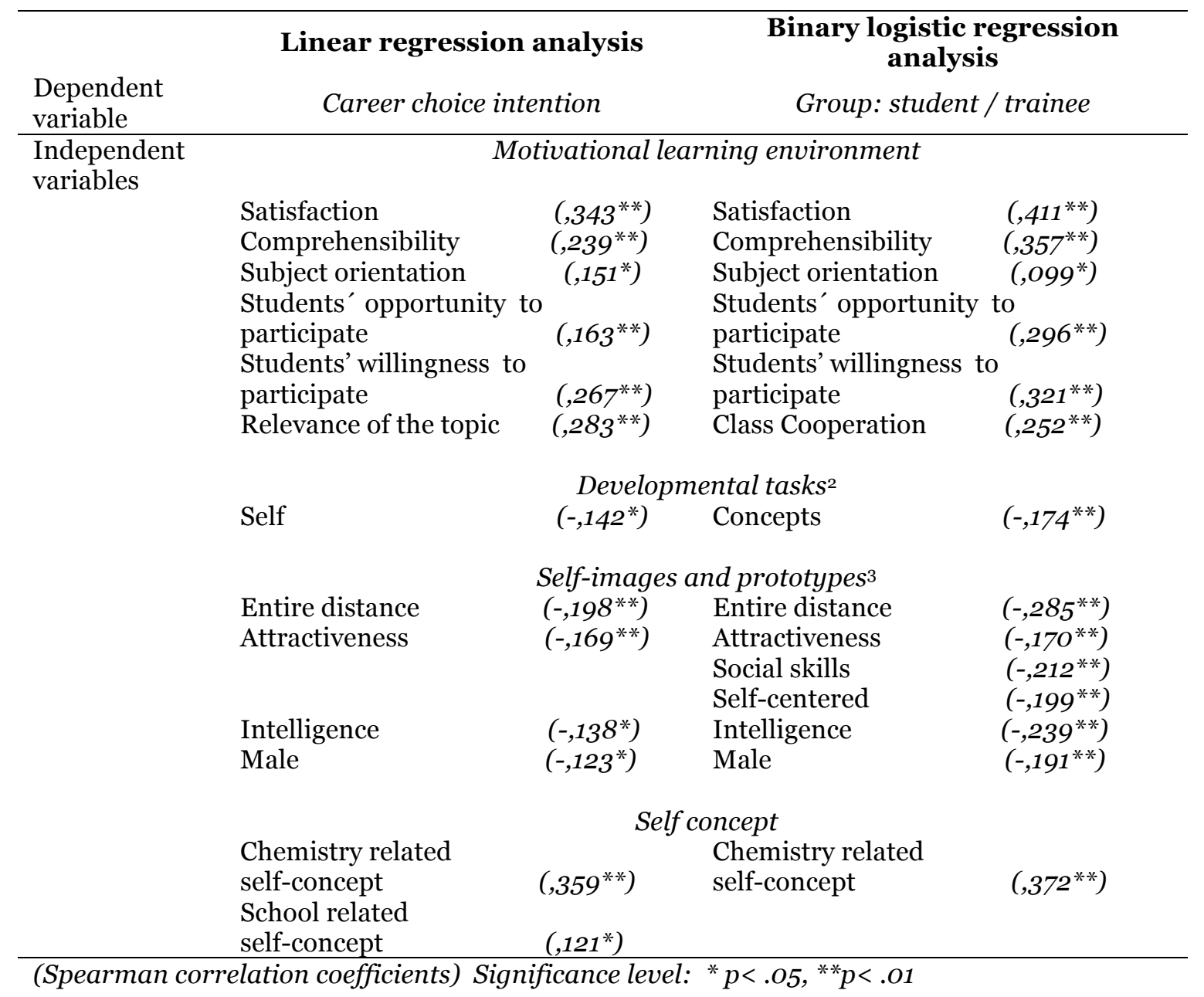

Based on the data of the Hauptschule-sample $(\mathrm{N}=324)$ we try to explain the reasons for career aspirations in the field of chemistry.

\footnotetext{
${ }^{1}$ For this analysis we decided to exclude 47 Hauptschule-students because they belong to the group of Hauptschule-students with ambitions to start a chemistry-related career after they will have finished school.

${ }^{2}$ Distance between priority (individual weighting) and praxis (presence in science classes)

${ }^{3}$ Distance between self-image and prototype
} 
After analysing the results in form of a linear regression analysis, we found the following model (Figure 2). Table 2 shows the most comprehensive model with the corresponding coefficients and model-fit-values.

Table 2 Results of the regression analysis. Influence of the different variables on the vocational choice.

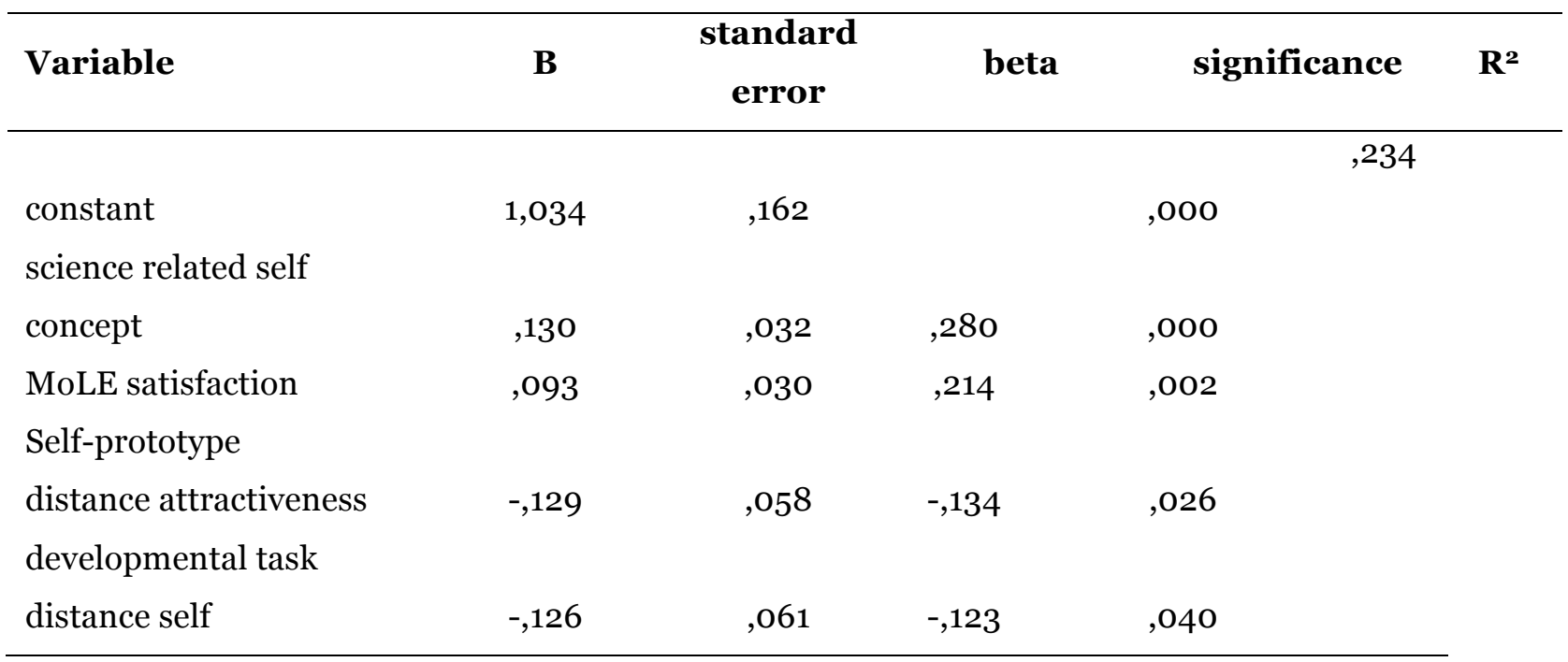

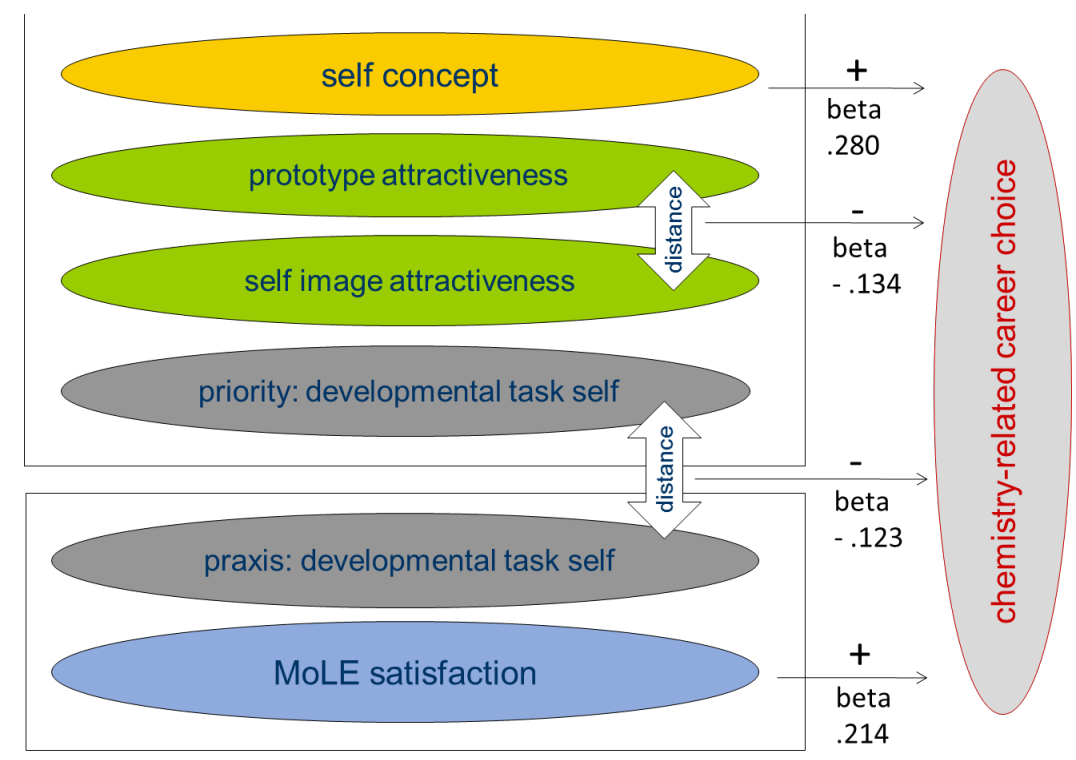

Figure 2 Influence of the different variables on the vocational choice; $\mathrm{R}^{2}=.234$ $+=$ positive influence, - = negative influence

We found that a positive science-related self-concept increases the likelihood of the student choosing a science-related career. Furthermore, we found one scale of the 
motivational learning environment which influences the career choice positively: satisfaction. A great distance between self-image and prototype in the scale attractiveness makes the choice of a science-related career less likely. The same we found for a great distance between the individual weighting (priority) of the developmental task self and their presence in science classes (praxis).

In the next step of our analysis we try to find out the reasons for choosing a chemistryrelated career. Table 3 shows the most comprehensive model with the corresponding coefficients and model-fit-values

Table 3. Results of the regression analysis. Influence of the different variables to the membership to the group student or trainee

\begin{tabular}{|c|c|c|c|c|c|}
\hline Variable & B & $\begin{array}{c}\text { standard } \\
\text { error }\end{array}$ & sig. & $\exp (B)$ & $\begin{array}{c}\text { Nagelkerke's } \\
\mathbf{R}^{\mathbf{2}} \\
\end{array}$ \\
\hline & & & & &, 530 \\
\hline $\begin{array}{l}\text { constant } \\
\text { science related }\end{array}$ & $-5,241$ & ,860 & ,ooo & ,005 & \\
\hline self-concept & 600 & ,149 & ,ooo & 1,821 & \\
\hline MoLE satisfaction & ,660 & ,122 & ,000 & 1,935 & \\
\hline $\begin{array}{l}\text { Self-prototype } \\
\text { distance social skills }\end{array}$ &,- 962 &, 341 & ,005 & ,382 & \\
\hline $\begin{array}{l}\text { developmental task } \\
\text { distance concepts }\end{array}$ & $-1,085$ & ,395 & ,006 & ,338 & \\
\hline
\end{tabular}

The logistic regression analysis led to the following model (see Figure 2). In the logistic regression analysis we found influences from the variables science related self-concept and MoLE satisfaction. A high score on these scales makes the membership to the group of the trainees more likely. Similarly, a great distance score on the scales social skills (selfprototype) and concepts (developmental tasks) makes the membership to the group of trainees more likely. 


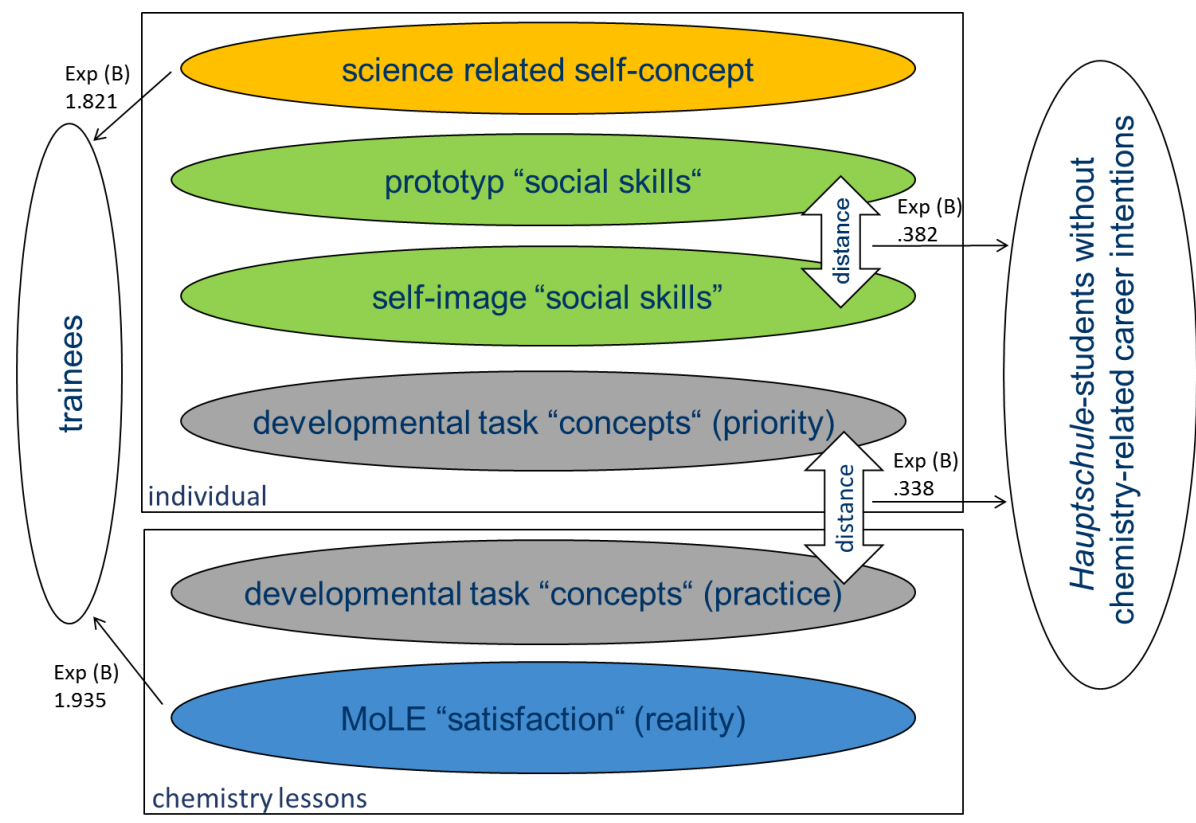

Figure 2 Influence of the different variables on the membership to the group of trainee or Hauptschule-student without chemistry-related career intentions.

\section{Discussion}

Regarding the linear regression analysis we can state that not all but some of the variables we examined are connected to "science-related career choice intention" in a statistic significant manner. In each of our four theoretical approaches we found one scale which seems to influence the career choice. The model-fit-value $\mathrm{R}^{2}$ expresses that $23.4 \%$ of the variance of students' "science-related career choice" intention can be explained by the model. The choice of career is a very complex construct which is influenced by many different aspects, which are often not related to school or chemistry lessons (Taskinen, 2010). However, an explanation of $23.4 \%$ is highly acceptable to us. Comparing these variables the "science-related self-concept" has the most important impact on the choice of career (beta .280). However, students' "satisfaction" in chemistry lessons seems to influence the career choice as well (beta .214).

Our second step was to compare the group of Hauptschule-students without chemistryrelated career intentions and the group of trainees in form of a logistic regression analysis. We found four variables influencing the group membership. The model-fit-value in this analysis is Nagelkerkes $\mathrm{R}^{2}$. It can be interpreted in the same way as $\mathrm{R}^{2}$ in the linear regression analysis. Nagelkerkes $\mathrm{R}^{2} .530$ expresses that the group membership can be explained by the independent variable to an extent of about $53 \%$ in a statistic significant manner. Following Backhaus et al. $(2003,448)$ this is an excellent model fit. The most 
important impact on the group membership has the "satisfaction" in chemistry lessons (exp (b) $=1,935)$ followed by the variable "science related self-concept" (exp (b) = 1,821).

All in all science education seems to influence students' career choice. With regard to the results of our analyses chemistry teaching should pay more attention to the practical aspects of people being employed in chemical industry and how they work and which interesting tasks and issues they are dealing with. It should be pointed out that those working in the field of science mostly do not fulfil the stereotypes the students express. By doing so, students are supported in choosing a scientific career (if this fits to their vocational interests as well) more. Furthermore aspects of chemistry lessons often considered less relevant could gain importance for students. In addition the motivational learning environment should be as satisfying as possible. According to Bolte (2004) a positive learning environment leads to better learning success. Our results show that students' satisfaction concerning the motivational learning environment can influence students' attitude to science-related careers.

In addition teachers should keep in mind that chemistry lessons should -according our results- support students in dealing with and coping their developmental tasks. All in all chemistry lessons which consider the aspects just mentioned could change and improve students' view on chemistry-related careers and enhance science education.

\section{References}

Aschbacher, P. R., Li, E., \& Roth, E. J. (2010). Is science me? High school students' identities, participation and aspirations in science, engineering, and medicine. Journal of Research in Science Teaching, 47(5), 564-582.

Backhaus, K., Erichson, B., Plinke, W., \& Weiber, R. (2003). Multivariate Analyseverfahren Eine anwendungsorientierte Einführung (10th ed.). Dordrecht: Springer.

Barman, C. R. (1999). Students' views about scientists and school science: Engaging K-8 teachers in a national study. Journal of Science Teacher Education, 1O(1), 43-54.

Bertels, N., \& Bolte, C. (2009). Developmental Tasks, Stereotypes and Motivational Learning Environments in Science Lessons (in Germany). In Proceedings of the Annual Meeting of the National Association for the Research on Science Education (NARST), Los Angeles, USA.

Bertels, N., \& Bolte, C. (2010). Occupational Orientation - A Foreign Concept to Chemistry Lessons. In Proceedings of the Annual Meeting of the National Association for the Research on Science Education (NARST), Philadelphia, USA.

Bertels, N., \& Bolte, C. (2015). Einflussfaktoren des Chemieunterrichts auf die Berufswahl von Schülerinnen und Schülern der Sekundarstufe 1. Zeitschrift für Didaktik der Naturwissenschaften (in progress)

Bolte, C. (2004). Motivationales Lernklima im Chemieunterricht. Praxis der Naturwissenschaften Chemie in der Schule, 53(7), 33-37.

Chambers, D. W. (1983). Stereotypic images of the scientist: The draw-a-scientist test. Science Education, 67(2), 255-265.

Dickhäuser, O., Schöne, C., Spinath, B., \& Stiensmeier-Pelster, J. (2002). Die Skalen zum akademischen Selbstkonzept. Zeitschrift für Differentielle und Diagnostische Psychologie, 23(4), 393-405. 
Eccles, J. S. (1983). Expectancies, Values and Academic Choice - Origins and Changes. In Spence, J. (Ed.), Achievement and Achievement Motivation. San Francisco, CA: W. H. Freeman.

Elster, D. (2009). Aus Bildung und Wissenschaft-Naturwissenschaftlicher Unterricht und Beruf. Mathematische und Naturwissenschaftliche Unterricht, 62(1), 4.

Hannover, B., \& Kessels, U. (2004). Self-to-prototype matching as a strategy for making academic choices. Why high school students do not like math and science. Learning and instruction, 14(1), 51-67.

Havighurst, R. J. (1981): Developmental Tasks and Education (3rd ed.). New York and London: Longman.

Kessels, U., \& Hannover, B. (2002). Die Auswirkungen von Stereotypen über Schulfächer auf die Berufswahlabsichten Jugendlicher. Pädagogische Psychologie unter gewandelten gesellschaftlichen Bedingungen, 53-67.

Köller, O., Daniels, Z., Schnabel, K., \& Baumert, J. (2000). Kurswahlen von Mädchen und Jungen im Fach Mathematik: Zur Rolle von fachspezifischem Selbstkonzept und Interesse. Zeitschrift für pädagogische Psychologie, 14(1), 26-37.

Marsh, H. W. \& Yeung, A. S. (1997). Coursework Selection: Relations to Academic Self-concept and Achievement. American Educational Research Journal, 34, 691-720.

Narayan, R., S. Park, D. Peker, B. Ding, J. Jang (2009). Students' Embodied Images of Scientists: aSculptured by Culture? An International Study. Proceedings of the Annual Meeting of the aNational Association for the Research on Science Education (NARST), Los Angles, USA.

Queisser, U. (2010). Zwischen Schule und Beruf: zur Lebensplanung und Berufsorientierung von Hauptschülerinnen und Hauptschülern. Julius Klinkhardt.

Seibert, H., \& Kleinert, C. (2009). Duale Berufsausbildung-Ungelöste Probleme trotz Entspannung. IAB Kurzbericht, 10, 2009.

Schenk, B. (2005). Entwicklungsaufgaben und Schule. In B. Schenk (Ed.), Bausteine einer Bildungsgangtheorie (pp. 275-289). Dordrecht: Springer.

Taskinen, P. H. (2010). Naturwissenschaften als zukünftiges Berufsfeld für Schulerinnen und Schuler mit hoher naturwissenschaftlicher und mathematischer Kompetenz: eine Untersuchung von Bedingungen für Berufserwartungen. Dissertation. Christian-Albrechts-Universität zu Kiel. 
BERTELS \& BOLTE 